\title{
Zn,Al hydrotalcites calcined at different temperatures: Preparation, characterization and photocatalytic activity in gas-solid regime
}

\author{
D. Carriazo ${ }^{\mathrm{a}, 1}$, M. del Arco $^{\mathrm{a}}$, E. García-López ${ }^{\mathrm{b}, *}$, G. Marcì $^{\mathrm{b}}$, C. Martín $^{\mathrm{a}}$, L. Palmisano $^{\mathrm{b}}$, V. Rives $^{\mathrm{a}}$ \\ a GIR-QUESCAT, Departamento de Química Inorgánica, Universidad de Salamanca, 37008 Salamanca, Spain \\ b "Schiavello-Grillone" Photocatalysis Group, Dipartimento di Ingegneria Elettrica, Elettronica e delle Telecomunicazioni, di Tecnologie Chimiche, \\ Automatica e Modelli Matematici (DIEETCAM), Università di Palermo, Viale delle Scienze, 90128 Palermo, Italy
}

\section{A R T I C L E I N F O}

\section{Article history:}

Received 7 February 2011

Received in revised form 13 April 2011

Accepted 21 April 2011

Available online 30 April 2011

\section{Keywords:}

Layered double hydroxides

Photocatalysis

$\mathrm{ZnAl}_{2} \mathrm{O}_{4}$

$\mathrm{ZnO}$

\begin{abstract}
A B S T R A C T
Layered double hydroxides (LDH) containing zinc and aluminium within the brucite-like layers and carbonate as the interlayer anion have been used as precursors for the preparation of mixed metal oxides by calcination. Zinc oxide and the $\mathrm{ZnAl}_{2} \mathrm{O}_{4}$ spinel were formed with different degree of crystallinity depending of two parameters, i.e., the $\mathrm{Zn}^{2+} / \mathrm{Al}^{3+}$ molar ratio and the calcination temperature $\left(500-800^{\circ} \mathrm{C}\right)$ of the $\mathrm{LDH}$ precursor. A pure spinel phase was obtained to remove $\mathrm{ZnO}$ upon a basic post-treatment in $\mathrm{NaOH}$ solution of the samples calcined at $800^{\circ} \mathrm{C}$. All the samples were tested for the photodegradation of 2-propanol in gas-solid regime. All the samples resulted active as heterogeneous photocatalysts. The photocatalytic activity increased by increasing the $\mathrm{Zn}^{2+} / \mathrm{Al}^{3+}$ molar ratio and the calcination temperature of the solids.
\end{abstract}

(c) 2011 Elsevier B.V. All rights reserved.

\section{Introduction}

There is an increasing demand for catalysts to eliminate the pollution associated to toxic compounds. Semiconductors such as $\mathrm{TiO}_{2}[1,2], \mathrm{ZnO}[3,4], \mathrm{SnO}_{2}$ or $\mathrm{CdS}$ [5] have been used in photocatalytic degradation of organic pollutants in liquid-solid [6] and in gas-solid regimes [7]. In addition to these oxides, it is worth studying the photoactivity of metal spinels, such as $\mathrm{ZnAl}_{2} \mathrm{O}_{4}$, which band gap, $3.8 \mathrm{eV}$ [8], makes it suitable for photocatalytic processes [9]. The classic route for preparation of semiconductor metal oxides photocatalysts, commonly obtained by calcination of salts, leads to solids with low specific surface area which is a disadvantage in heterogeneous catalysis. To avoid this problem various preparation methods such as sol-gel processes have been proposed [10]. The sol-gel methodology allows to obtain materials with high specific surface area, but the nature of the precursors, generally metal alkoxides, makes it very expensive. An alternative preparation method is the calcination of layered double hydroxides (LDHs), also known as hydrotalcite-like compounds or anionic clays [11-14]. These materials are layered solids with positively charged sheets, due to isomorphic substitution of divalent cations by trivalent ones in brucite layers, and charge-balancing anions in

\footnotetext{
* Corresponding author. Tel.: +39 091 23863784; fax: +39 0917025020.

E-mail address: elisaisabel.garcialopez@unipa.it (E. García-López).

1 Current address: Instituto de Ciencia de Materiales de Madrid, CSIC, Cantoblanco, 28049 Madrid, Spain.
}

the interlayer space. These solids can be described by the general formula $\left[\mathrm{M}^{3+}{ }_{x} \mathrm{M}^{2+}{ }_{1-x}(\mathrm{OH})_{2}\right]^{x+}\left[\mathrm{A}^{n-}\right]_{x / n} \mathrm{mH}_{2} \mathrm{O}$ where $\mathrm{M}^{2+}$ and $\mathrm{M}^{3+}$ are the divalent and the trivalent cation, respectively, and $\mathrm{A}^{n-}$ the exchangeable anion in the interlayer, where water molecules are also found. LDHs easy preparation, low cost and physico-chemical properties have allowed many applications for these materials as catalysts, catalyst supports and precursors, adsorbents, drug matrices, etc. [11-13]. The LDH compounds as prepared or calcined by a controlled decomposition are often used as catalysts or catalyst precursors. LDHs calcination have resulted to be an excellent methodology to prepare mixed oxides with better catalytic performance than conventional preparations, such as ceramic or wet chemical routes. For instance, Qi et al. have recently conducted studies on a mixed oxide catalyst prepared by calcination of LDHs which exhibited a comparable activity, but better stability compared with a commercial Cu-based catalyst [15]. Also Li et al. have reported that pure spinel ferrites can be obtained by calcination of tailored hydrotalcite-like layered double hydroxides [16]. These authors report that the main advantage of this preparation methodology is that the uniform distribution of metal cations in the LDH precursors drives to the formation of spinel ferrites in shorter time and requiring a much lower temperature.

In this work, $\mathrm{Zn}, \mathrm{Al}$ hydrotalcites with different $\mathrm{Zn}^{2+} / \mathrm{Al}^{3+}$ molar ratios and carbonate as the interlayer anion have been prepared. After their calcination at different temperatures $\left(500-800^{\circ} \mathrm{C}\right)$ the photocatalytic activity of the materials was tested for 2propanol oxidation in gas-solid regime. Photocatalytic oxidation of 2-propanol by using various types of solids is a widely studied 
reaction and different degradation pathways are reported depending upon the physico-chemical features of the solid [17]. Moreover, pure $\mathrm{ZnAl}_{2} \mathrm{O}_{4}$ spinel was obtained by selective leaching of $\mathrm{ZnO}$ from the hydrotalcites calcined at high temperature and their photocatalytic activity was also tested.

\section{Experimental}

\subsection{Samples preparation}

\subsubsection{Synthesis of $\mathrm{Zn} / \mathrm{Al}$ hydrotalcite precursors and oxides}

$\mathrm{Zn} / \mathrm{Al}$ hydrotalcite samples with carbonate in the interlayer (denoted hereafter as $\mathrm{Zn} / \mathrm{Al}-\mathrm{CO}_{3} \mathrm{LDHs}$ ) have been prepared by the standard co-precipitation method from metal salts [14]. $\mathrm{Zn}$ and $\mathrm{Al}$ nitrates, in adequate quantities to get a molar $\mathrm{Zn} / \mathrm{Al}$ ratio of 2 or 3 , were added to a basic solution containing $\mathrm{NaOH}(2 \mathrm{M})$ and $\mathrm{Na}_{2} \mathrm{CO}_{3}$ (1 M), at $\mathrm{pH} 9$ and $40^{\circ} \mathrm{C}$. The suspension, kept under constant magnetic stirring during the addition of the salts, was further stirred for $24 \mathrm{~h}$ at $70^{\circ} \mathrm{C}$. The resulting filtered powder was finally washed, centrifuged and dried in air. The obtained samples were named as $\mathrm{Zn} / \mathrm{Al}-2$ and $\mathrm{Zn} / \mathrm{Al}-3$, depending on the nominal $\mathrm{Zn} / \mathrm{Al}$ molar ratio. They were calcined at $500,600,700$ or $800^{\circ} \mathrm{C}$ for $2 \mathrm{~h}$, leading to the final solids which are named as the parent sample, followed by the calcination temperature in Celsius.

\subsubsection{Synthesis of $\mathrm{ZnAl}_{2} \mathrm{O}_{4}$ spinels}

Since calcination of hydrotalcites usually leads to formation of a mixture of the spinel and the oxide of the divalent cation, a pure spinel was obtained by selective leaching of $\mathrm{ZnO}$ from samples $\mathrm{Zn} / \mathrm{Al}-3-700$ and $\mathrm{Zn} / \mathrm{Al}-3-800$. A portion of $2 \mathrm{~g}$ of the $\mathrm{Zn} / \mathrm{Al}-3-700$ or $\mathrm{Zn} / \mathrm{Al}-3-800$ solid was added to $50 \mathrm{ml}$ of $\mathrm{NaOH} 10 \mathrm{M}$ and kept for $48 \mathrm{~h}$ at $60^{\circ} \mathrm{C}$ under moderate agitation. The resulting suspension was centrifuged and washed several times until complete elimination of sodium and then dried at $80^{\circ} \mathrm{C}$ overnight. The samples obtained were labelled as S-700 and S-800.

\subsection{Characterization of the solids}

Chemical analyses for Zn and Al were carried out in Servicio General de Análisis Químico Aplicado (Universty of Salamanca, Spain) in a model ULTIMA-2 ICP-OES spectrophotometer from Jovin Yvon, after dissolving the samples in nitric acid. Carbon was analyzed in an Elemental Analyzer from Leco, model CHNS 932. The powder Xray diffraction (PXRD) patterns were collected on a Siemens D-500 diffractometer using $\mathrm{Cu} K \alpha$ radiation $(\lambda 1.54050 \AA)$ and quartz as an external standard. The textural properties were studied from the $\mathrm{N}_{2}$ adsorption-desorption isotherms, recorded at $-196^{\circ} \mathrm{C}$ in a Gemini instrument from Micromeritics. The samples were previously outgassed at $120^{\circ} \mathrm{C}$ for $2 \mathrm{~h}$. Scanning electron microscopy (SEM) was performed using a FEI QUANTA 200-F ESEM microscope, operating at $20 \mathrm{kV}$ on specimens upon which a thin layer of gold had been evaporated. The diffuse reflectance spectra (DRS) were obtained in air at room temperature in the wavelength range $800-250 \mathrm{~nm}$ using a Shimadzu UV-2401 PC spectrophotometer, with $\mathrm{BaSO}_{4}$ as the reference material.

\subsection{Photoreactivity experiments}

The photoreactor operating in the gas-solid regime was a cylindrical shaped batch type Pyrex fixed bed photoreactor $(V=150 \mathrm{ml}$, $\Phi=93 \mathrm{~mm}$, height $=22 \mathrm{~mm}$ ). The photocatalyst $(0.1 \mathrm{~g})$ was simply dispersed as a thin layer inside the photoreactor and the corresponding fixed bed height was ca. $1 \mathrm{~mm}$. In this tightly closed reactor, after purging with pure $\mathrm{O}_{2}$ during $30 \mathrm{~min}, 10 \mu \mathrm{L}$ of liquid 2-propanol was injected and quickly vaporized with an infrared gun. The initial concentration of 2 -propanol was $8.7 \times 10^{-4} \mathrm{M}$.

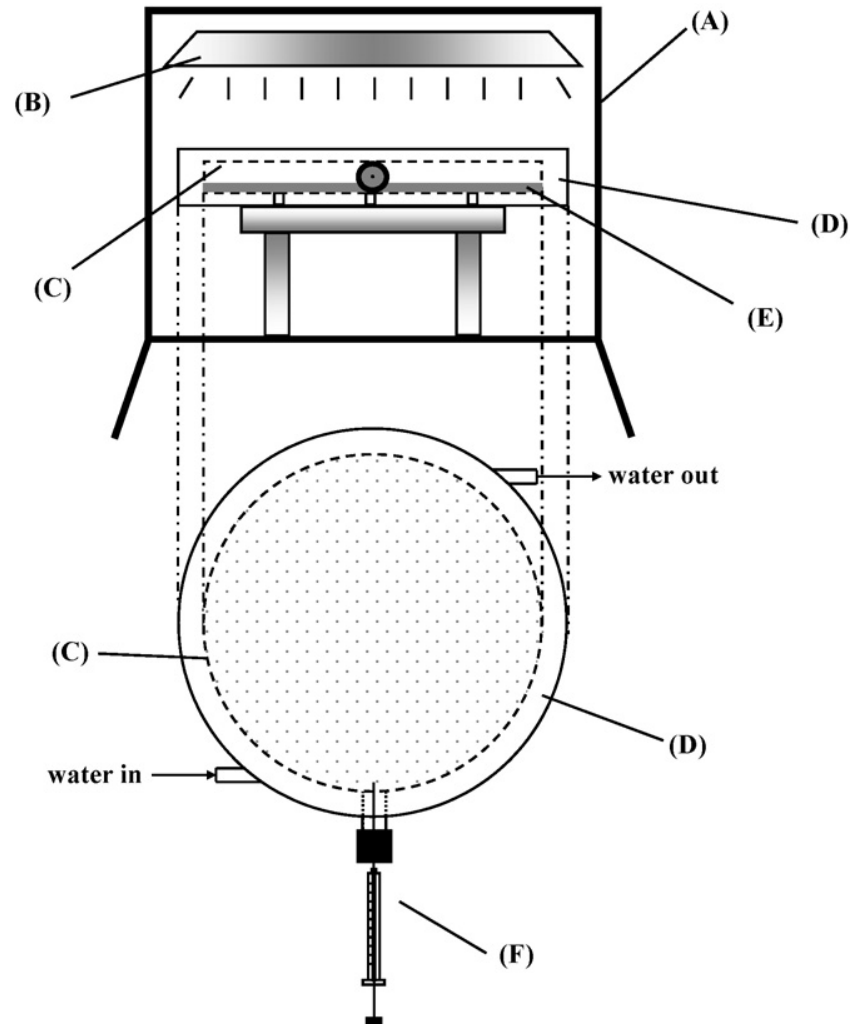

Scheme 1. Set up of the photoreactive system: (A) Solarbox; (B) lamp; (C) photoreactor; (D) water cooling jacket; (E) photocatalyst; and (F) gas-tight syringe.

The reactor, provided with a water cooling jacket, was horizontally positioned and illuminated from the top inside a SOLARBOX apparatus (CO.FO.ME.GRA.) equipped with a solar simulating lamp (1500 W high pressure Xe lamp). The set-up of the photoreactivity system is shown in Scheme 1.

Irradiation started only after the achievement of steady state conditions, i.e., after maintaining the system under dark conditions at room temperature to obtain the adsorption equilibrium of the substrate onto the catalyst surface. The irradiance reaching the photoreactor was measured by using a UVX Digital radiometer and it was equal to $1.0 \mathrm{~mW} \mathrm{~cm}^{-2}$ at a wavelength of $365 \mathrm{~nm}$. The runs lasted ca. $5 \mathrm{~h}$ and the reacting fluid was analyzed by withdrawing gas samples from the photoreactor by means of a gas-tight syringe. The concentrations of the substrate and of the intermediates were measured by a GC-17A Shimadzu gas chromatograph equipped with a HP-1 column and a FID, whereas carbon dioxide was analyzed by a 60/80 Carboxen 1000 column in an HP6890 gas chromatograph equipped with a TCD.

\section{Results and discussion}

\subsection{Bulk and textural samples characterization}

Fig. 1 reports the PXRD patterns of the original hydrotalcite samples and of the oxides obtained after their calcination. The diffractograms of the uncalcined $\mathrm{Zn} / \mathrm{Al}-2$ and $\mathrm{Zn} / \mathrm{Al}-3$ samples are characteristic of well crystallized solids with the hydrotalcite-like structure. The only appreciable difference between them is the relative intensity of the diffraction lines, which appears sharper and more intense for Zn/Al-2 sample, indicating a higher degree of crystallinity in this solid [18]. The diffraction patterns of both materials show the peaks corresponding to the crystallographic planes $(00 l)$ in a relatively symmetrical sequence indicating a high level of order in the stacks. The basal spacing values corresponding to diffraction 


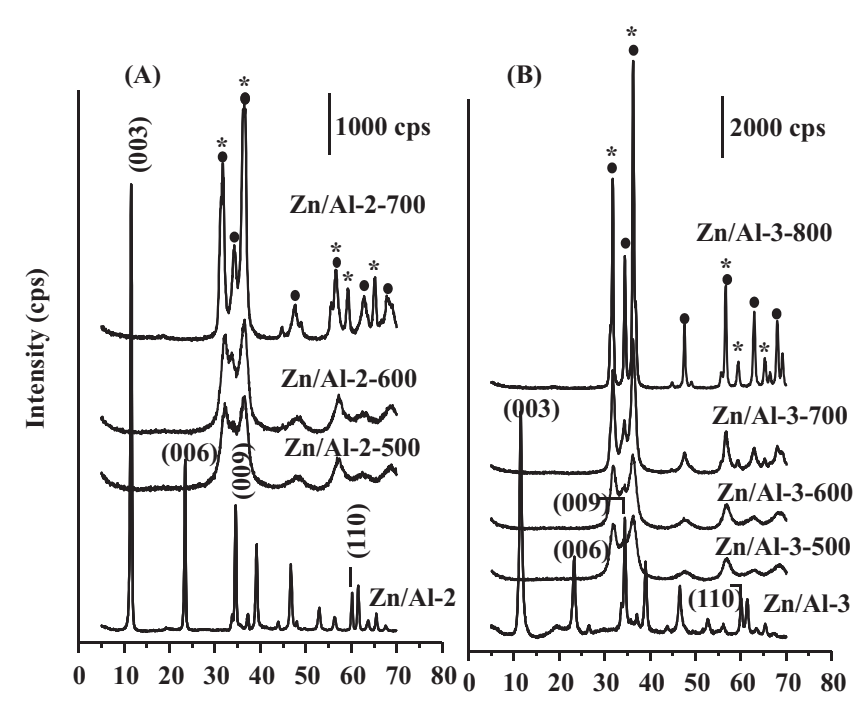

$2 \theta, \mathrm{Cu} \mathrm{K \alpha}$
Fig. 1. PXRD diffractograms of $\mathrm{Zn} / \mathrm{Al}-2$ (A) and $\mathrm{Zn} / \mathrm{Al}-3$ (B) series. (•) $\mathrm{ZnO}$ zincite $\left({ }^{*}\right)$ $\mathrm{ZnAl}_{2} \mathrm{O}_{4}$. Crystallographic parameters of the $\mathrm{Zn} / \mathrm{Al}-2$ and $\mathrm{Zn} / \mathrm{Al}-3: a=3.02 \pm 0.01 \AA$ and $c=23.7 \pm 0.1 \AA$.

by planes (003) and (006) and the crystallographic parameters $\boldsymbol{a}$ and $\boldsymbol{c}$, calculated from the positions of the diffraction lines corresponding to (110) and (003) planes, respectively [19], are in agreement with those calculated by other authors for similar samples $[9,20,21]$. Both diffraction patterns also show very low intense lines that can be tentatively ascribed to the presence of a crystalline $\mathrm{ZnO}$ phase dispersed over the brucite-like layers.

Calcination of the samples at $500^{\circ} \mathrm{C}$ leads to the collapse of the lamellar structure and new diffraction lines ascribed to different metal oxides, $\mathrm{ZnO}$ and the $\mathrm{ZnAl}_{2} \mathrm{O}_{4}$ spinel, appear (see Fig. 1). These diffraction maxima are much weaker than those of the previous hydrotalcite-like phase, indicating the lower crystallinity of these phases. Patzkó et al. [21] previously reported that calcination at $500^{\circ} \mathrm{C}$ is not enough to induce the formation of aluminium oxide crystals and they suggested that only $\mathrm{ZnO}$ crystallizes at this temperature, whereas $\mathrm{Al}$ is present as $\mathrm{AlO}(\mathrm{OH})$. On the contrary Zou et al. [9] claimed that crystallization of both $\mathrm{ZnO}$ (zincite) and $\mathrm{ZnAl}_{2} \mathrm{O}_{4}$ spinel occurred at $500^{\circ} \mathrm{C}$, and they reported that the use of hydrotalcite as the starting material for the formation of the spinel required short time and low temperature. In another study, Zhao et al. [22] considered that $\mathrm{Al}^{3+}$ cations are homogeneously dispersed in a mostly amorphous phase and they are leached at $500^{\circ} \mathrm{C}$ from $\mathrm{ZnO}$, giving rise to formation of spinel phase. It can be also observed in Fig. 1 that calcination at higher temperatures $\left(>500^{\circ} \mathrm{C}\right)$ resulted in an increase in the crystallinity of both $\mathrm{ZnO}$ and $\mathrm{ZnAl}_{2} \mathrm{O}_{4}$, as suggested by the higher intensity and sharpness of the maxima due to both phases.

$\mathrm{Zn} / \mathrm{Al}-3-700$ and $\mathrm{Zn} / \mathrm{Al}-3-800$ samples were treated with a $\mathrm{NaOH}$ solution at $60^{\circ} \mathrm{C}$ in order to selectively remove the $\mathrm{ZnO}$ phase by dissolution. Fig. 2 reports the PXRD of the resulting samples (S-700 and S-800) where only peaks due to the $\mathrm{ZnAl}_{2} \mathrm{O}_{4}$ spinel can be observed. These peaks are particularly sharp for sample S-800.

Chemical analysis data (atomic absorption) of the samples indicated that the amounts of $\mathrm{Zn}$ and $\mathrm{Al}$ for the $\mathrm{Zn} / \mathrm{Al}-2$ (36.1\% $\mathrm{Zn}, 7.5 \% \mathrm{Al})$ and $\mathrm{Zn} / \mathrm{Al}-3(48.9 \% \mathrm{Zn}, 7.3 \% \mathrm{Al})$ samples are in acceptable agreement with the nominal $\mathrm{Zn} / \mathrm{Al}$ molar ratio in the pristine solution during preparation of the hydrotalcites, which evidenced that the co-precipitation was nearly complete. The results, by taking into account also carbon analyses, allowed to calculate the following formulae: $\left[\mathrm{Zn}_{0.66} \mathrm{Al}_{0.33}(\mathrm{OH})_{2}\right]\left(\mathrm{CO}_{3}\right)_{0.17} \cdot n \mathrm{H}_{2} \mathrm{O}$ and

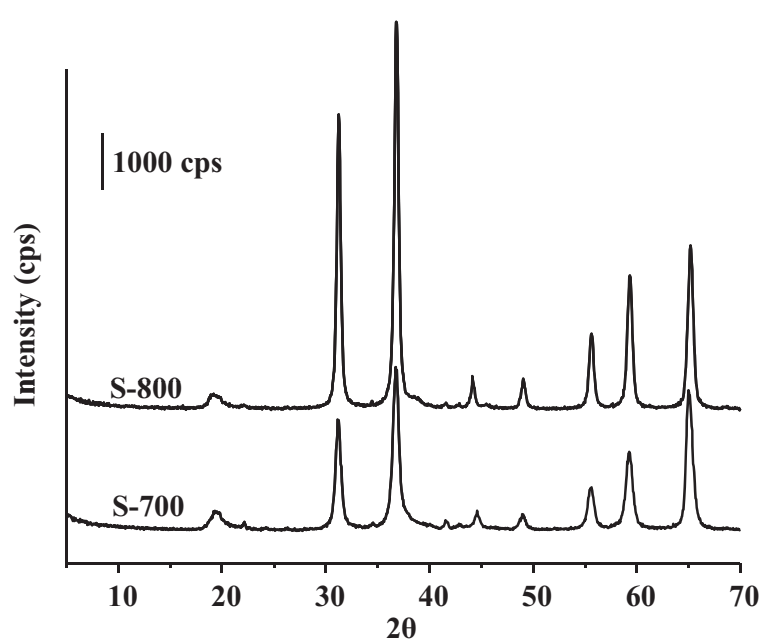

Fig. 2. PXRD diffractograms for (a) S-700 and (b) S-800.

$\left[\mathrm{Zn}_{0.73} \mathrm{Al}_{0.27}(\mathrm{OH})_{2}\right]\left(\mathrm{CO}_{3}\right)_{0.14} \cdot n \mathrm{H}_{2} \mathrm{O}$, for the solids $\mathrm{Zn} / \mathrm{Al}-2$ and $\mathrm{Zn} / \mathrm{Al}-$ 3 , respectively.

As expected, the metal molar ratios measured, reported in Table 1, did not change significantly after the thermal treatments at different temperatures. The decrease of the $\mathrm{Zn}$ percentage in the samples after the treatment with $\mathrm{NaOH}$ confirmed dissolution of the $\mathrm{ZnO}$ phase. This was more evident for sample S-800 in which the measured $\mathrm{Zn} / \mathrm{Al}$ molar ratio was close to 0.5 , which corresponds to the theoretical ratio in a pure $\mathrm{ZnAl}_{2} \mathrm{O}_{4}$ spinel phase. Moreover, these measurements indicate also that $\mathrm{ZnO}$ is not completely leached in sample $\mathrm{S}-700$, because the $\mathrm{Zn} / \mathrm{Al}$ molar ratio corresponds to 1.42 .

To study the textural properties of all of the samples, the adsorption-desorption isotherms of $\mathrm{N}_{2}$ at $-196^{\circ} \mathrm{C}$ have been recorded. Fig. 3 shows the isotherms of some selected samples and Table 1 includes the values of the BET specific surface areas (SSA).

Calcination of samples at $500^{\circ} \mathrm{C}$ led to an increase in the SSA, due to the destruction of the lamellar structure giving rise to the formation of low crystalline $\mathrm{ZnO}$ and $\mathrm{ZnAl}_{2} \mathrm{O}_{4}$ phases The crystallinity increased by increasing the calcination temperature and, therefore, the SSA values significantly decreased, as reported in Table 1 . Calcination at $800^{\circ} \mathrm{C}$ gave rise to sintering of the oxides and consequently to a strong decrease of their specific surface areas. Treatment with $\mathrm{NaOH}$ solution, for $\mathrm{ZnO}$ removal, led to an increase of their specific surface areas. Sample S-800 exhibited a specific surface area three times higher than that of the untreated sample and a pore volume ten times larger $\left(0.02 \mathrm{~cm}^{3} \mathrm{~g}^{-1}\right.$ for the calcined sam-

Table 1

Molar ratio $\mathrm{Zn} / \mathrm{Al}$ in the samples, band gap of the powders, specific surface areas (SSA) and amount of $\mathrm{CO}_{2}$ evolved per unit of surface area after $5 \mathrm{~h}$ of photocatalytic reaction.

\begin{tabular}{lllll}
\hline Sample & Zn/Al molar ratio & E gap $[\mathrm{eV}]$ & $\mathrm{SSA}\left[\mathrm{m}^{2} \mathrm{~g}^{-1}\right]$ & $\mathrm{CO}_{2}\left[\mathrm{~mol} / \mathrm{m}^{2}\right]$ \\
\hline Zn/Al-2 & 1.99 & - & 20 & \\
$\mathrm{Zn} /$ Al-3 & 2.77 & - & 53 & \\
$\mathrm{Zn} /$ Al-2-500 & 2.01 & n.m. & 64 & Absent \\
Zn/Al-2-600 & 1.99 & 3.65 & 45 & Absent \\
Zn/Al-2-700 & 2.10 & 3.30 & 25 & $1.9 \times 10^{-6}$ \\
Zn/Al-3-500 & 2.88 & 3.32 & 84 & $1.6 \times 10^{-6}$ \\
Zn/Al-3-600 & 2.83 & 3.41 & 72 & $3.2 \times 10^{-6}$ \\
Zn/Al-3-700 & 3.02 & 3.33 & 48 & $5.6 \times 10^{-6}$ \\
Zn/Al-3-800 & 3.20 & 3.30 & 18 & $1.7 \times 10^{-5}$ \\
S-700 & 1.42 & 3.20 & 57 & $2.6 \times 10^{-6}$ \\
S-800 & 0.50 & - & 50 & $1.4 \times 10^{-6}$ \\
ZnO Aldrich & - & 3.20 & 19 & $1.3 \times 10^{-5}$ \\
\hline
\end{tabular}

(n.m. = not measured). 


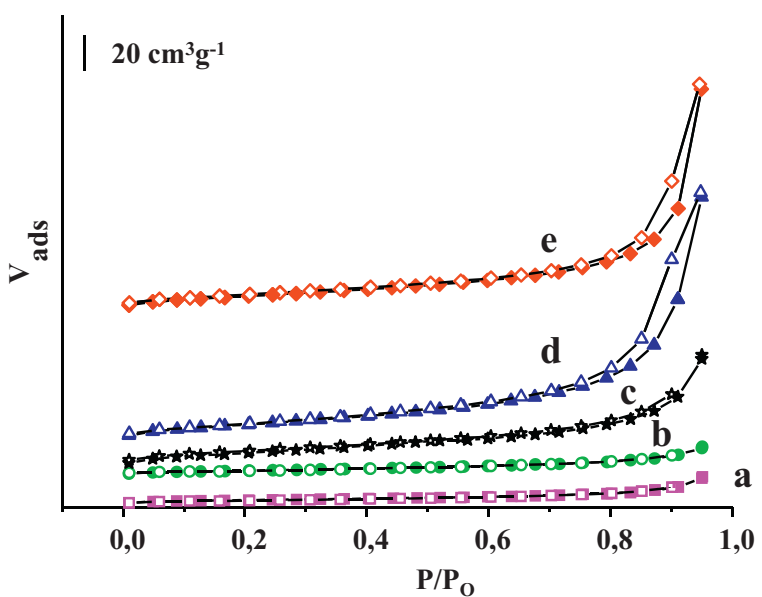

Fig. 3. Nitrogen adsorption-desorption isotherms (filled symbols and open symbols, respectively) at $-196^{\circ} \mathrm{C}$ for (a) Zn/Al-2; (b) Zn/Al-3-800; (c) Zn/Al-3-500; (d) S-700 and (e) S-800.

ple and $0.2 \mathrm{~cm}^{3} \mathrm{~g}^{-1}$ for sample $\mathrm{S}$-800). The adsorption-desorption isotherms are characteristic of nonrestricted multilayer adsorption on nonporous samples and they correspond to the type II according to the IUPAC classification [23]. Samples S-700 and S-800 obtained after the $\mathrm{ZnO}$ leaching are an exception to this behaviour, as their isotherms are characteristic of mesoporous solids (type IV of the IUPAC classification). The latter also exhibits a H3 hysteresis loop, indicating some asymmetry of the pores.

From SEM observations (see Figs. 4 and 5), it can be concluded that the platelet-like morphology of the starting hydrotalcite samples was maintained for both $\mathrm{Zn} / \mathrm{Al}-2$ and $\mathrm{Zn} / \mathrm{Al}-3$ sets of samples, without any appreciable difference up to a temperature of $700^{\circ} \mathrm{C}$. Calcination at $800^{\circ} \mathrm{C}$ produced the collapse of this morphology and larger particles with rounded edges are observed. The morphology of samples S-700 and S-800 is completely different from that of the samples not treated with $\mathrm{NaOH}$. Indeed, they consist of aggregates of particles with sizes of ca. $30 \mathrm{~nm}$ and $90 \mathrm{~nm}$ for samples S-700 and S-800, respectively. The higher increase of SSA (from 18 to $50 \mathrm{~m}^{2} \mathrm{~g}^{-1}$ ) for $\mathrm{Zn} / \mathrm{Al}-3-800$ and S-800 in respect to $\mathrm{Zn} / \mathrm{Al}-3-700$ and S-700 (from 48 to $57 \mathrm{~m}^{2} \mathrm{~g}^{-1}$ ) (see Table 1 ), can be attributed to the complete removal of $\mathrm{ZnO}$ in sample S-800 (consisting of $\mathrm{ZnAl}_{2} \mathrm{O}_{4}$ ) and to the residual presence of $\mathrm{ZnO}$ in sample S-700.

Fig. 6 shows the diffuse reflectance spectra of the calcined $\mathrm{Zn} / \mathrm{Al}$ 2 and -3 samples. All calcined $\mathrm{Zn} / \mathrm{Al}-2$ and -3 samples showed the typical broad absorption band that can be ascribed to the charge transfer process from $\mathrm{O}^{2-}$ to $\mathrm{Zn}^{2+}$ responsible for the $\mathrm{ZnO}$ band-gap. The only exception is sample Zn/Al-2-500, (Fig. 6(a)) whose spectrum shows a step. When the calcination temperature increased (see sample Zn/Al-2-600, Fig. 6(b)), this step disappeared. A further increase of the calcination temperature gave rise to a shift to lower energies; indeed, absorption of sample $\mathrm{Zn} / \mathrm{Al}-2-600$ starts at ca. $370 \mathrm{~nm}$ (Fig. 6(b)), whereas the absorption of sample $\mathrm{Zn} / \mathrm{Al}-2$ 700 starts at ca. $425 \mathrm{~nm}$ (Fig. 6(c)). As far as the calcined Zn/Al-3 sample concerns, the spectrum for sample Zn/Al-3-500 (Fig. 6(d)) shows only a broad absorption band that is shifted to higher energies for the $\mathrm{Zn} / \mathrm{Al}-3-600$ sample (Fig. 6(e)), but again, as in the case of the $\mathrm{Zn} / \mathrm{Al}-2$ samples, it is shifted to lower energies for samples calcined at a higher temperature (Zn/Al-3-700, Fig. 6(f)).

Since the band gaps for $\mathrm{ZnAl}_{2} \mathrm{O}_{4}$ and $\mathrm{ZnO}$ are reported to be 3.8 and $3.2 \mathrm{eV}$, respectively [8], the shift to higher energies in the absorption edge could be due to a more important presence of the spinel structure at $600^{\circ} \mathrm{C}$ with respect to $500^{\circ} \mathrm{C}$, in agreement with the PXRD diffractograms. Moreover, when the calcination temperature increased from 600 up to $800^{\circ} \mathrm{C}$ the crystallinity of the $\mathrm{ZnO}$ particles increased (see Fig. 1) and consequently the absorption by this material is recorded at lower energies.

The presence of the step in the spectrum of the $\mathrm{Zn} / \mathrm{Al}-2-500$ sample, which is absent in the spectrum of sample $\mathrm{Zn} / \mathrm{Al}-3-500$, can be due to the fact that the spectrum of sample $\mathrm{Zn} / \mathrm{Al}-2-500$
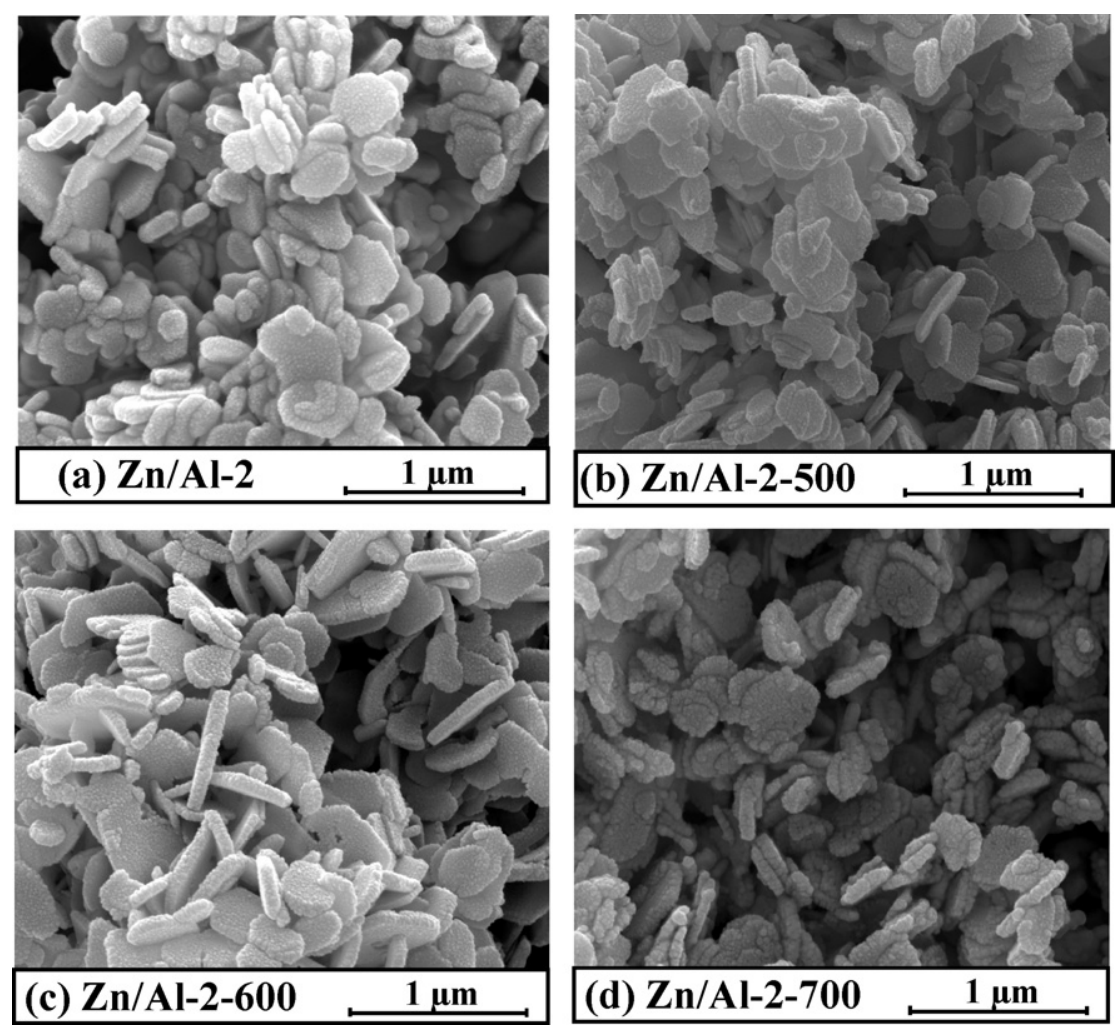

Fig. 4. SEM micrographs for (a) Zn/Al-2; (b) Zn/Al-2-500; (c) Zn/Al-2-600 and (d) Zn/Al-2-700. 


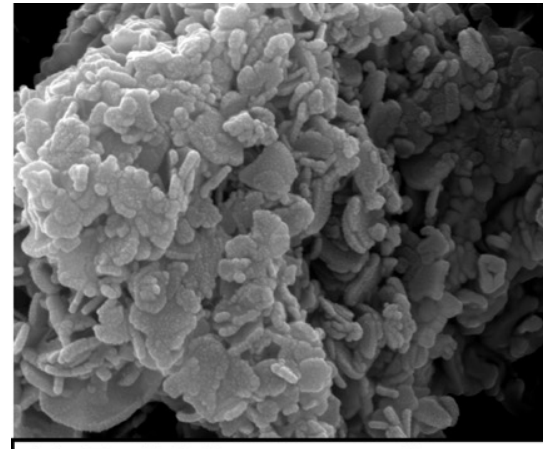

(a) Zn/Al-3
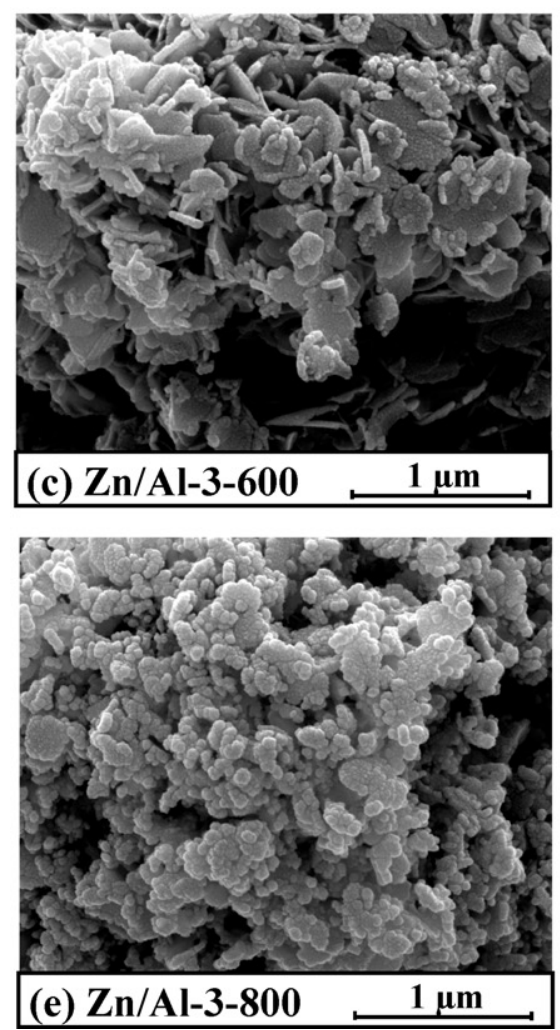
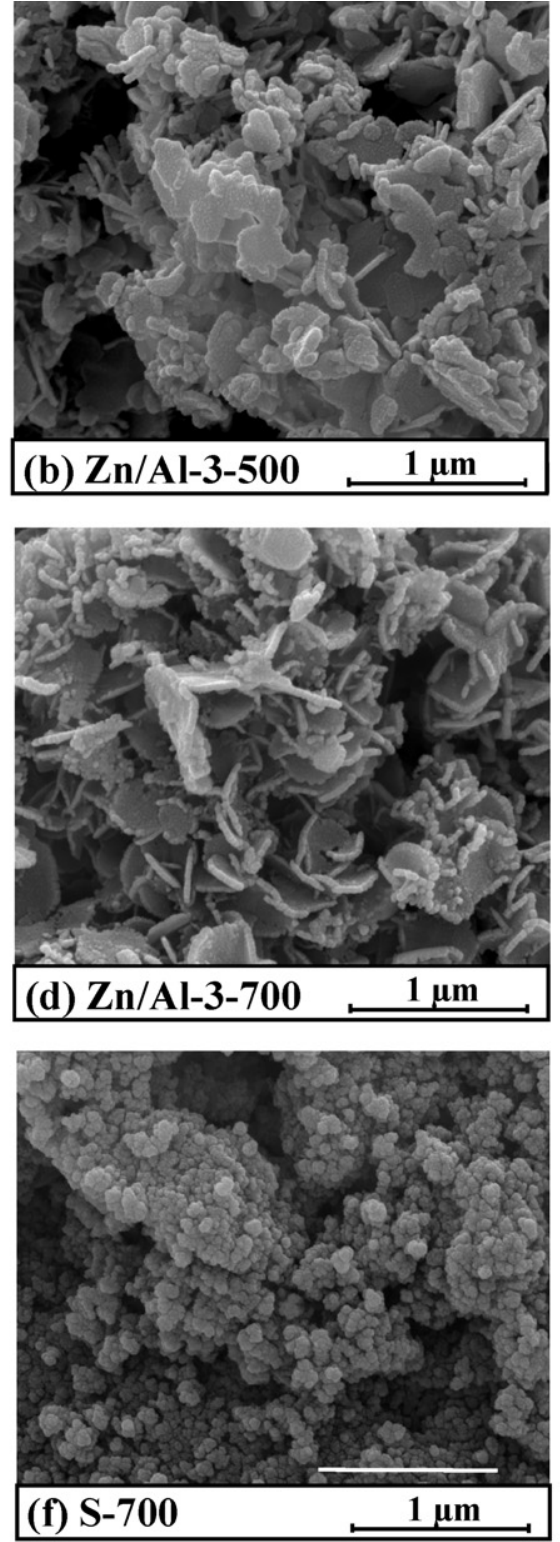

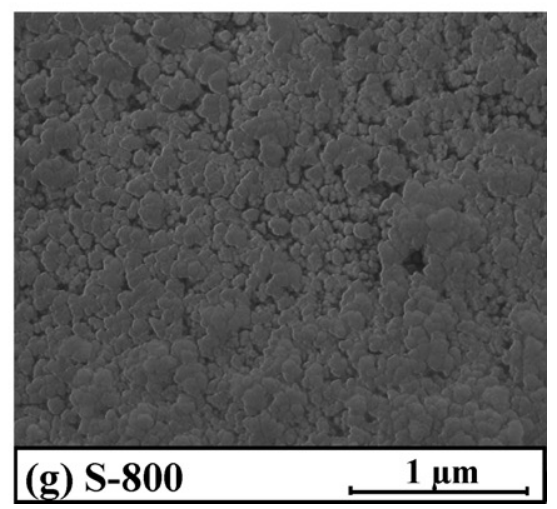

Fig. 5. SEM micrographs for (a) Zn/Al-3; (b) Zn/Al-3-500; (c) Zn/Al-3-600; (d) Zn/Al-3-700; (e) Zn/Al-3-800; (f) S-700 and (g) S-800.

could be influenced by the presence of the parent $\mathrm{Zn} / \mathrm{Al}-2$ hydrotalcite because the amount of $\mathrm{ZnO}$ formed at $500^{\circ} \mathrm{C}$ was still very low. On the contrary, for sample $\mathrm{Zn} / \mathrm{Al}-3-500$, with a higher $\mathrm{Zn}$ content, the amount of $\mathrm{ZnO}$ formed at $500^{\circ} \mathrm{C}$ was enough to produce the $\mathrm{ZnO}$ typical reflectance spectrum. It is worth noting that both uncalcined hydrotalcite samples, $\mathrm{Zn} / \mathrm{Al}-2$ and $\mathrm{Zn} / \mathrm{Al}-3$, show DRS spectra (not shown for the sake of brevity) where the reflectance increases from $80 \%$ to $100 \%$ starting from ca. $375 \mathrm{~nm}$. This wavelength value corresponds to the inflection point in the spectrum of $\mathrm{Zn} / \mathrm{Al}-2-500$ reported in Fig. 6(a).

$\mathrm{ZnO}$ is an indirect semiconductor [24] and the band gap energies of the samples, estimated from the tangent lines in the plots of the modified Kubelka-Munk function, $\left[F\left(R_{\infty}^{\prime}\right) h v\right]^{1 / 2}$ vs. the energy of exciting light [25], give rise to band-gap values ranging between 3.20 and $3.65 \mathrm{eV}$, as reported in Table 1 . The band gap values decrease by increasing the calcination temperature indicating that the $\mathrm{ZnO}$ crystalline phase was predominant on respect to the spinel one, both for Zn/Al-2 and Zn/Al-3 samples. From element chemical analysis data and bearing in mind that in the well crystallized samples (i.e., those calcined at high temperature) $\mathrm{Zn}$ is present as $\mathrm{ZnO}$ and as the spinel, while the only Al-containing phase is the spinel, we can conclude that sample $\mathrm{Zn} / \mathrm{Al}-2-700$ contains $57 \% \mathrm{ZnO}$ and $43 \%$ spinel (mass percentage), while for sample $\mathrm{Zn} / \mathrm{Al}-3-800$ these values were 67 and 33\%, respectively.

The inset in Fig. 6 shows the DRS spectra for samples S-700 and S-800. Sample S-700 shows the typical broad band spectrum, indicating the presence of a small amount of $\mathrm{ZnO}$. However the spectrum for sample S-800 is dramatically different and the features can be attributed to those ascribed to the pure spinel structure, in agreement with the chemical analyses and literature [26].

\subsection{Photoreactivity experiments}

Blank reactivity experiments were performed under the same experimental conditions used for the photo-reactivity runs but in the absence of catalyst, oxygen or light. No reactivity was observed in all these cases so that it was concluded that the simultaneous presence of $\mathrm{O}_{2}$, catalyst, and irradiation was needed for degradation of 2-propanol. The solid samples showed strong adsorption of the substrate under dark conditions. The photore- 


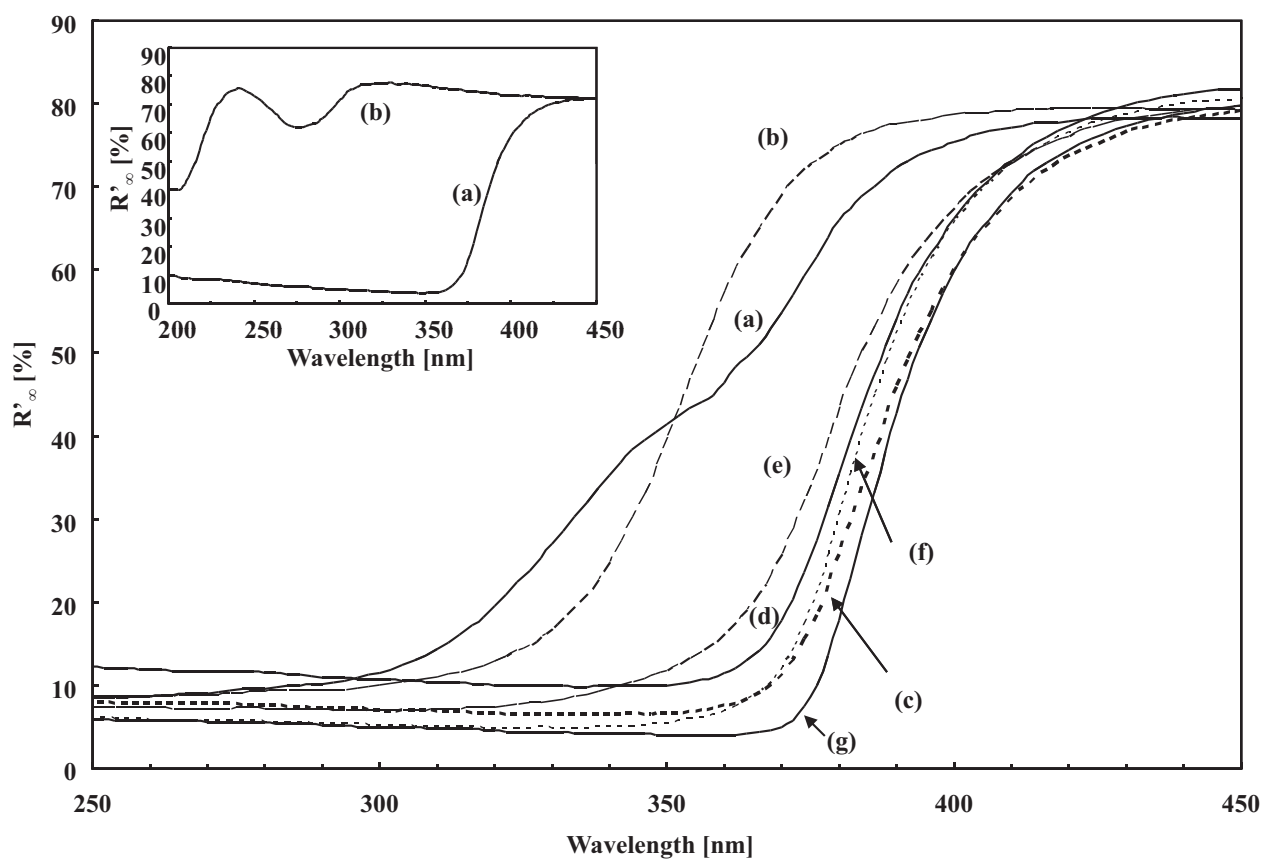

Fig. 6. Diffuse reflectance spectra of: (a) Zn/Al-2-500; (b) Zn/Al-2-600; (c) Zn/Al-2-700; (d) Zn/Al-3-500; (e) Zn/Al-3-600; (f) Zn/Al-3-700 and (g) Zn/Al-3-800. Inset: (a) S-700 and (b) S-800.

activity runs started after the system achieved the steady state conditions in the darkness, i.e., when the concentration of 2propanol remained constant with time (ca. $1 \mathrm{~h}$ was necessary). Fig. 7 reports the values of 2-propanol concentration vs. irradiation time for runs carried out in the presence of calcined $\mathrm{Zn} / \mathrm{Al}-2$ and $\mathrm{Zn} / \mathrm{Al}-3$ samples. As above mentioned, a strong adsorption of the substrate was observed because the concentration of 2propanol in the gas phase at steady state conditions resulted ca. $10-20 \%$ of the initial one (see Fig. 7). Concerning $\mathrm{Zn} / \mathrm{Al}-2$ and $\mathrm{Zn} / \mathrm{Al}-3$ powders calcined at $500^{\circ} \mathrm{C}$ (Fig. 7 (a) and (d)), a moderate photo/thermodesorption was observed during the first stages of the photocatalytic run. 2-Propanol slow desorption throughout all
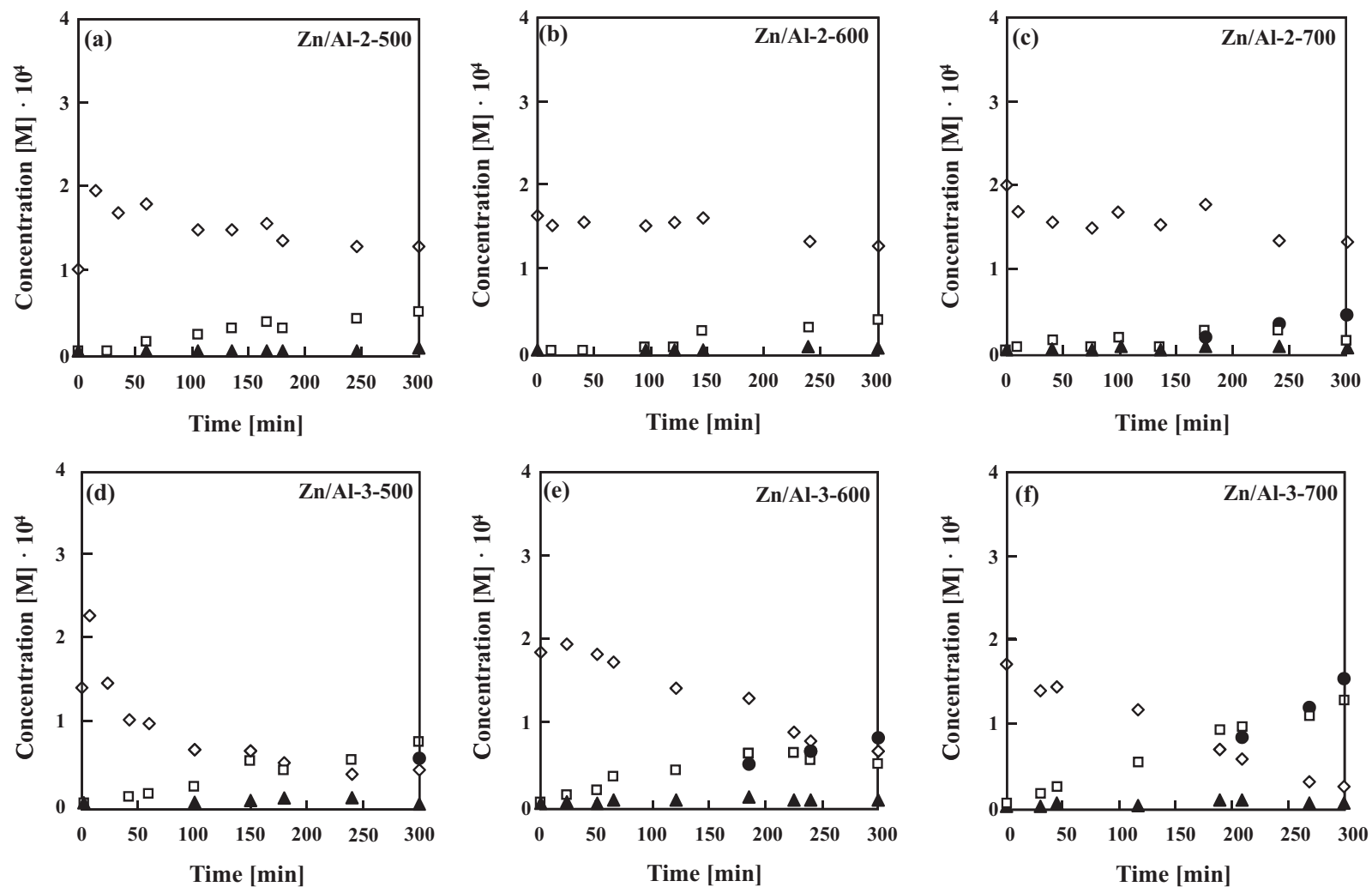

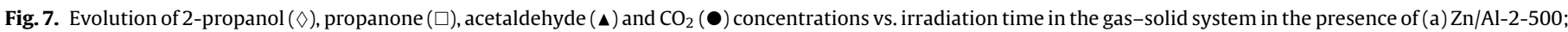
(b) Zn/Al-2-600; (c) Zn/Al-2-700; (d) Zn/Al-3-500; (e) Zn/Al-3-600 and (f) Zn/Al-3-700. 

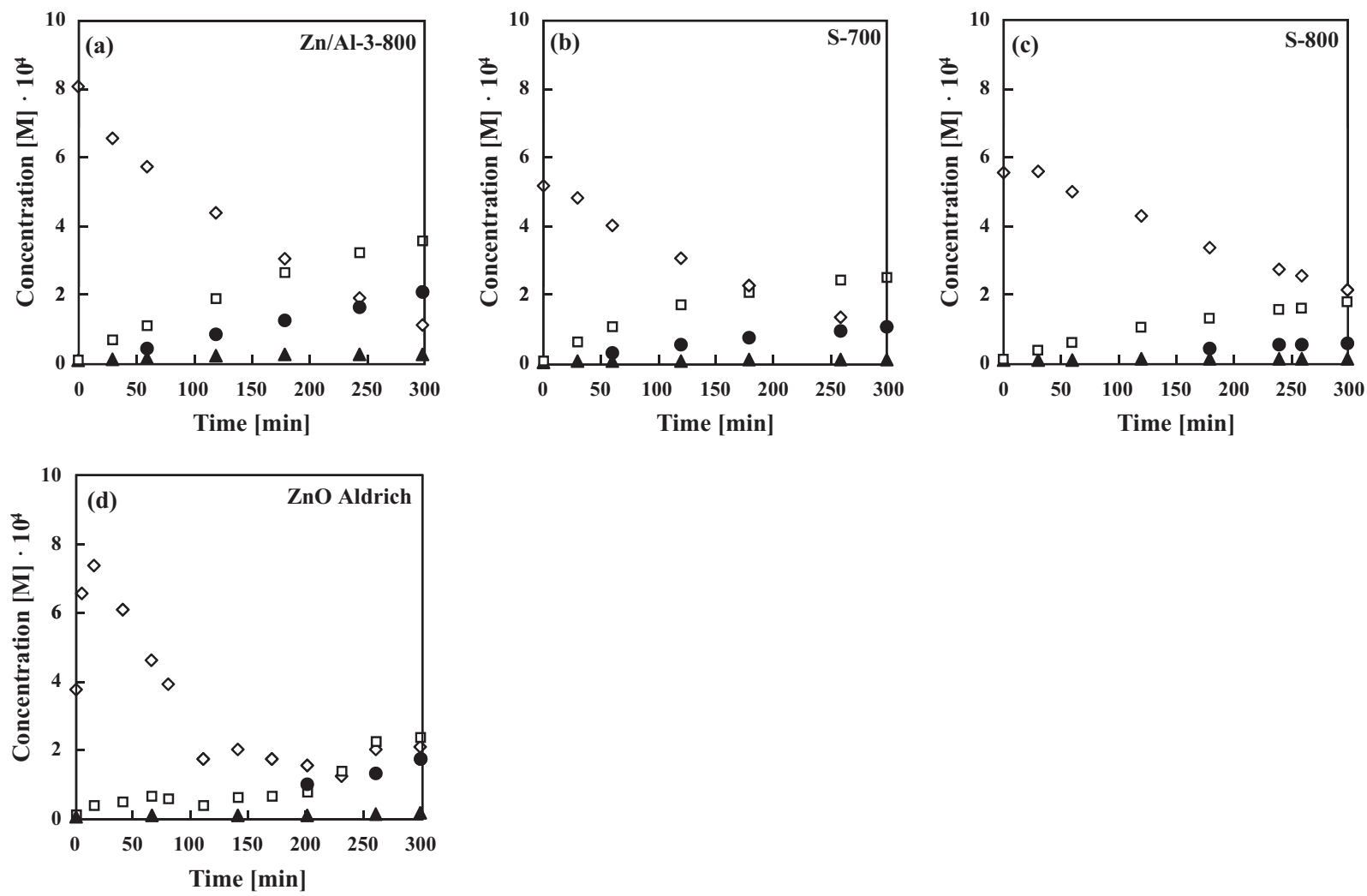

Fig. 8. Evolution of 2-propanol $(\diamond)$, propanone $(\square)$, acetaldehyde $(\boldsymbol{\Delta})$ and $\mathrm{CO}_{2}$ (b) S-700; (c) S-800 and (d) ZnO Aldrich.

the runs probably occurred simultaneously to the photo-oxidation reaction. A decrease of 2-propanol concentration is clearly evident only in Fig. 7(f). In any case, 2-propanol was adsorbed and then desorbed during the photocatalytic runs, although it is possible to establish that its photo-oxidation actually occurred, as propanone and acetaldehyde were found [17]. Carbon dioxide was also detected in the runs carried out by using all the three calcined $\mathrm{Zn} / \mathrm{Al}-3$ samples, whereas total oxidation of 2-propanol to $\mathrm{CO}_{2}$ and $\mathrm{H}_{2} \mathrm{O}$ occurred only in the presence of $\mathrm{Zn}-\mathrm{Al}-2-700$.

The perusal of Fig. 7 reveals that both parameters, calcination temperature (as reported also for $\mathrm{TiO}_{2}$ prepared in sophisticated way [27]) and $\mathrm{Zn}$ content, strongly influenced the photo-catalytic behaviour. As far as $\mathrm{Zn} / \mathrm{Al}-3$ samples are concerned, the total oxidation of 2-propanol, for instance, slightly increased by increasing the calcination temperature. This increase of activity can be attributed to the increasing amount of $\mathrm{ZnO}$ in the sample. Table 1 reports the amount of $\mathrm{CO}_{2}$ obtained after $5 \mathrm{~h}$ of photocatalytic reaction that accounts for the activity of the powder under investigation. It is possible to establish, as a general trend, that the photocatalytic activity increased by increasing the calcination temperature and by increasing the $\mathrm{Zn}$ content in the powders; indeed, $\mathrm{Zn} / \mathrm{Al}-3-700$ was the most photoactive sample (see Fig. 7). In order to ascertain this trend a $\mathrm{Zn} / \mathrm{Al}-3$ sample calcined at $800^{\circ} \mathrm{C}$ was prepared. Fig. 8(a) reports the evolution of 2-propanol, intermediates and $\mathrm{CO}_{2}$ during the photocatalytic run and it is evident that this sample showed to be more photo-active than the $\mathrm{Zn} / \mathrm{Al}-3-700$ one. It is worth noting that no strong adsorption of 2-propanol, observed in the previous $\mathrm{Zn} / \mathrm{Al}-3$ samples, occurred. Actually the initial concentration of the substrate almost coincides with the nominal initial amount (Fig. 8(a)).

This behaviour could be attributed to different morphological and physico-chemical properties of the $\mathrm{Zn} / \mathrm{Al}-3-800$ sample in respect to the $\mathrm{Zn} / \mathrm{Al}-3-500, \mathrm{Zn} / \mathrm{Al}-3-600, \mathrm{Zn} / \mathrm{Al}-3-700$ samples. SEM observations indicate a platelet-like morphology for the samples calcined up to $700^{\circ} \mathrm{C}$, whereas the sample calcined at $800^{\circ} \mathrm{C}$ shows a collapse of this feature with formation of rounded edges particles. The almost spherical shape of the particles along with their very low specific surface area could be responsible for the less significant adsorption of 2-propanol.

The photocatalytic reaction by using $\mathrm{Zn} / \mathrm{Al}-3-800$ proceeded also with formation of propanone, acetaldehyde and carbon dioxide. The amount of $\mathrm{CO}_{2}$ obtained by using this sample, reported in Table 1, was the maximum among the $\mathrm{Zn} / \mathrm{Al}$ samples, indicating that the increase of the calcination temperature and $\mathrm{Zn}$ content had a positive effect on the activity of the powder.

Fig. 8 also reports the photocatalytic activity of samples S-700 and S-800 (obtained after samples $\mathrm{Zn} / \mathrm{Al}-3-700$ and 800 were submitted to a treatment with $\mathrm{NaOH}$ in order to eliminate $\mathrm{ZnO}$ ).

2-Propanol adsorption in dark conditions (see Figs. 7(f) and 8) was lower for S-700 than for the untreated powder Zn/Al-3-700. This lower adsorption ability can be explained by considering the collapse of the platelet like structure (Fig. 5), due to the $\mathrm{NaOH}$ treatment that, as reported above, seems to favour 2-propanol adsorption. On the contrary, S-800 sample showed a higher adsorption ability than sample $\mathrm{Zn} / \mathrm{Al}-3-800$, probably due to the presence of porosity (Fig. 3 ) related to the absence of a platelet like structure and a higher SSA (Table 1 ).

As far as the photoactivity of S-700 and S-800 is concerned, the reactivity seems to decrease with the calcination temperature (less propanone and $\mathrm{CO}_{2}$ were formed) but this behaviour is due to the fact that S-800 consists only of spinel (less active than $\mathrm{ZnO}$ ) while S-700 still contains $\mathrm{ZnO}$.

For the sake of comparison with the home prepared samples, a run was carried out with bare commercial $\mathrm{ZnO}$ (Aldrich). The initial concentration of substrate in the gas phase resulted lower than $8.7 \times 10^{-4} \mathrm{M}$, due to the adsoption of 2-propanol onto the surface 
of the photocatalyst under dark conditions, whereas an initial photodesorption of 2-propanol was observed during the photocatalytic reaction, and propanone, traces of acetaldehyde and $\mathrm{CO}_{2}$ were found. A perusal of Table 1 indicates that 2-propanol was photooxidized more efficiently in the presence of $\mathrm{Zn} / \mathrm{Al}-3-800$; indeed, a more significant amount of $\mathrm{CO}_{2}$ was produced in the presence of the latter sample than in the presence of commercial $\mathrm{ZnO}$.

\section{Conclusions}

Two series of $\mathrm{Zn}, \mathrm{Al}-\mathrm{CO}_{3}$ layered double hydroxides (LDH) with different $\mathrm{Zn}^{2+} / \mathrm{Al}^{3+}$ molar ratios have been prepared and used as precursors to obtain composites containing $\mathrm{ZnO}$ and $\mathrm{ZnAl}_{2} \mathrm{O}_{4}$. By varying both the $\mathrm{Zn}^{2+} / \mathrm{Al}^{3+}$ molar ratio during the preparation of the $\mathrm{LDH}$ precursor and the calcination temperature $\left(500-800^{\circ} \mathrm{C}\right)$ of the LDH solids with different characteristics were obtained.

For both $\mathrm{Zn}^{2+} / \mathrm{Al}^{3+}$ molar ratios, solids already from $500{ }^{\circ} \mathrm{C} \mathrm{ZnO}$ and $\mathrm{ZnAl}_{2} \mathrm{O}_{4}$ were formed and the crystallinity of these two phases increased by increasing the calcination temperature.

A pure spinel phase was obtained upon a basic post-treatment in $\mathrm{NaOH}$ solution of the samples calcined at $800^{\circ} \mathrm{C}$. All the samples were tested for the photodegradation of 2-propanol in gas-solid regime and all of them resulted active as heterogeneous photocatalysts. Propanone was obtained as a major intermediate product whereas acetaldehyde was also identified. $\mathrm{CO}_{2}$, as the final oxidation product, appeared only when $\mathrm{Zn} / \mathrm{Al}-2-700$ and calcined $\mathrm{Zn} / \mathrm{Al}-3$ samples were used. The photocatalytic activity of the samples, evaluated by the amount of $\mathrm{CO}_{2}$ produced, increased by increasing the $\mathrm{Zn}^{2+} / \mathrm{Al}^{3+}$ molar ratio and the calcination temperature of the solids. This finding can be attributed to the increase of the $\mathrm{ZnO}$ amount and of the crystallinity of the solids. Zn/Al-3-800 was the most photoactive sample and showed to be more photoactive also than a commercial $\mathrm{ZnO}$ sample. After treatment of some selected samples with $\mathrm{NaOH}$ to partially or completely remove $\mathrm{ZnO}$, the photocatalytic activity decreased, indicating that the $\mathrm{ZnO}$ phase was more active than the $\mathrm{ZnAl}_{2} \mathrm{O}_{4}$ spinel one.

\section{Acknowledgements}

G.M., E.G.L. and L.P. wish to thank MIUR and INCA for financial support. D.C., M.A., C.M., and V.R. acknowledge financial support from MEC (Grant MAT2009-08526).

\section{References}

[1] M. Addamo, V. Augugliaro, A. Di Paola, E. García-López, V. Loddo, G. Marcì, R. Molinari, L. Palmisano, M. Schiavello, J. Phys. Chem. B 108 (2004) 3303-3310.

[2] S. Liu, J. Yu, M. Jaroniec, J. Am. Chem. Soc. 132 (2010) 11914-11916.

[3] (a) G. Marcì, V. Augugliaro, M.J. López-Muñoz, C. Martín, L. Palmisano, V. Rives, M. Schiavello, R.J.D. Tilley, A.M. Venezia, J. Phys. Chem. B 105 (2001) 1026-1032;

(b) G. Marcì, V. Augugliaro, M.J. López-Muñoz, C. Martín, L. Palmisano, V. Rives, M. Schiavello, R.J.D. Tilley, A.M. Venezia, J. Phys. Chem. B 105 (2001) 1033-1040.

[4] J. Yu, X. Yu, Environ. Sci. Technol 42 (2008) 4902-4907.

[5] S.K. Kansal, M. Singh, D. Sud, J. Hazard. Mater. 141 (2007) 581-590.

[6] R. Comparelli, E. Fanizza, M.L. Curri, P.D. Cozzoli, G. Mascolo, A. Agostiano, Appl. Catal. B 60 (2005) 1-11.

[7] (a) S. Brosillon, L. Lhomme, C. Vallet, A. Bouzaza, D. Wolbert, Appl. Catal. B 78 (2008) 232-241;

(b) V. Augugliaro, S. Coluccia, E. García-López, V. Loddo, G. Marcì, G. Martra, L. Palmisano, M. Schiavello, J. Catal. 235 (2005) 209-220.

[8] S.K. Sampath, J.F. Cordaro, J. Am. Ceram. Soc. 81 (1998) 649-654.

[9] L. Zou, F. Li, X. Xiang, D.G. Evans, X. Duan, Chem. Mater. 18 (2006) 5852-5859.

[10] C.J. Brinker, G.W. Scherer, Sol-Gel Science, Academic Press, Boston, 1990.

[11] F. Cavani, F. Trifiró, A. Vaccari, Catal. Today 11 (1991) 173-301.

[12] V. Rives (Ed.), Study of Layered Double Hydroxides: Present and Future, Nova Sci. Pub., New York, 2001.

[13] D. Carriazo, M. Del Arco, C. Martín, V. Rives, Appl. Clay Sci. 37 (2007) 231-239.

[14] W.T. Reichle, Solid State Ionics 22 (1986) 135-141.

[15] C. Qi, J.C. Amphlett, B.A. Peppley, Appl. Catal. A 302 (2006) 237-243.

[16] F. Li, J. Liu, D.G. Evans, X. Duan, Chem. Mater. 16 (2004) 1597-1602.

[17] G. Marcì, E. García-López, L. Palmisano, D. Carriazo, C. Martín, V. Rives, Appl. Catal. B 90 (2009) 497-506.

[18] C. Busetto, G. Del Piero, G. Manara, F. Trifiró, A. Vaccari, J. Catal. 85 (1984) 260-266.

[19] G.W. Brindley, S. Kikkawa, Am. Miner. 64 (1979) 836-843.

[20] E.M. Seftel, E. Popovici, M. Mertens, K. Witte, G. Tendeloo, P. Cool, E.F. Vansant, Micropor. Mesopor. Mater. 113 (2008) 296-304.

[21] A. Patzkó, R. Kun, V. Hornok, I. Dekany, T. Engelhardt, N. Schall, Colloid Surf. A Physicochem. Eng. Aspects 265 (2005) 64-72.

[22] X. Zhao, F. Zhang, S. Xu, D.G. Evans, X. Duan, Chem. Mater. 22 (2010) 3933-3942.

[23] K.S.W. Sing, D.H. Everett, R.A.W. Haul, L. Moscou, R. Pierotti, J. Rouquerol, T. Sieminiewska, Pure Appl. Chem. 57 (1985) 603-620.

[24] C. Wang, Q. Li, B. Mao, E. Wang, C. Tian, Mater. Lett. 62 (2008) 1339-1341.

[25] J. Torrent, V. Barrón, Encyclopedia of Surface and Colloidal Science, Marcel Decker Inc., New York, 2002.

[26] S.F. Wang, F. Gu, M.K. Lü, X.F. Cheng, W.G. Zou, G.J. Zhou, S.M. Wang, Y.Y. Zhou, J. Alloy Compd. 394 (2005) 255-258.

[27] J. Yu, B. Wang, Appl. Catal. B 94 (2010) 295-302. 